\title{
Ficus Dubia Latex Extract Prevent DMH-Induced Rat Colorectal Carcinogenesis Through the Regulation of Xenobiotic Metabolism, Inflammation, Cell Proliferation and Apoptosis
}

\section{Rentong Hu}

Department of Biochemistry, Faculty of Medicine, Chiang Mai University

Weerachai Chantana

Department of Biochemistry, Faculty of Medicine, Chiang Mai University

Pornsiri Pitchakarn

Department of Biochemistry, Faculty of Medicine, Chiang Mai University

\section{Subhawat Subhawa}

Department of Biochemistry, Faculty of Medicine, Chiang Mai University

\section{Bhanumas Chantarasuwan}

National Science Museum, Technopolish

Piya Temviriyanukul

Food and Nutrition Academic and Research Cluster, Institute of Nutrition, Mahidol University

Teera Chewonarin ( $\square$ teera.c@cmu.ac.th )

Department of Biochemistry, Faculty of Medicine, Chiang Mai University

\section{Research Article}

Keywords:

Posted Date: January 24th, 2022

DOI: https://doi.org/10.21203/rs.3.rs-1165152/v1

License: (c) (1) This work is licensed under a Creative Commons Attribution 4.0 International License. Read Full License 


\section{Abstract}

Ficus dubia latex is recognized as a remedy in Asian traditional medicine with various therapeutic effects. The present study aimed to determine the preventive action of Ficus dubia latex extract (FDLE) on 1,2dimethylhydrazine (DMH) -induced rat colorectal carcinogenesis and its mechanisms. The experiment included an initiation model in which rats were orally administered with FDLE daily for one week before $\mathrm{DMH}$ injection until the end of the experiment, while only after $\mathrm{DMH}$ injection until the end in the postinitiation model. The results firstly indicated that FDLE treatment could reduce the level of methylazoxymethanol (MAM) in rat colonic lumen by inhibition of the activities of both phase I xenobiotic metabolizing enzymes in the liver and $\beta$-glucuronidase in the colon, leading to reduced DNA methylation in colonic mucosal cells, related to the number of ACF in the initiation stage. Besides, FDLE modulated the inflammation which could suppress the growth and induce apoptosis of aberrant colonic mucosal cells, leading to retardation of ACF multiplicity. Therefore, FDLE showed the ability to suppress the DMH-induced rat ACF formation and inflammation promoted growth of ACF. In conclusion, FDLE had the potential to prevent multistage colorectal carcinogenesis in rat received carcinogens.

\section{Introduction}

Colorectal cancer is the third most recurrently diagnosed cancer and the fourth most likely cause of cancer mortality worldwide with increasing incidence in recent years ${ }^{1}$. Nowadays, the chemopreventive strategies using dietary supplements and natural active compounds show potential for the protection of humans against colorectal cancer in its early stages ${ }^{2,3}$.

DMH-induced colorectal carcinogenesis has been established to study the chemopreventive effect of test compounds in a variety of mechanisms ${ }^{4}$. With regard to the DMH-induced rat model, aberrant crypt foci (ACF) are indicators for the early stages of colorectal carcinogenesis in rats, which is associated with promoting cell proliferation and a low apoptotic rate, resulting in colonic crypts in the colon ${ }^{5,6}$. Whereas, inflammation is considered to be an important risk factor for the progression of many cancers ${ }^{7}$ and it also promotes cell proliferation by activating proliferating cell nuclear antigen (PCNA) which, as a typical marker of cell proliferation, has an important role in DNA synthesis and DNA repair during the cell cycle from $\mathrm{G} 1$ phase to $S$ phase ${ }^{8}$. Therefore, to inhibit inflammation and cell proliferation or to induce cell apoptosis becomes an effective strategy to slow down the progression of cancer ${ }^{9,10}$.

Ficus dubia, as a new Ficus species, is abundantly found in tropical Asia, including southern Thailand, Malaysia and Sumatra. Only a few reports have shown that its latex extract had anti-inflammatory activity in lipopolysaccharide-induced macrophages and that its sap extract had anti-oxidant activity in skin $^{11,12}$. Especially, its latex was utilized as an ingredient in traditional drugs, due to a belief in its health benefits, unsupported by any scientific data about its anti-tumor activity. However, research has found that the anti-tumor biological activities of other Ficus species have been reported. For example, Ficus racemose contains a high content of flavonoids which had anti-diabetes, anti-inflammatory, anti-oxidant 
and anti-proliferation properties ${ }^{13,14}$. The latex of Ficus carica showed an inhibitory effect on the proliferation of several cancer cells ${ }^{15,16}$. Therefore, the present study aims to evaluate the anti-tumor efficacy of Ficus dubia latex extract on DMH-induced rat colorectal carcinogenesis by investigating xenobiotic metabolism, inflammation, cell proliferation and apoptosis.

\section{Results}

\section{Phytochemical composition analysis of FDLE}

Total amounts of phenolic acids and flavonoids in FDLE were shown in Table 1. The total phenolic and flavonoid content of FDLE were $341.6 \pm 5.4 \mathrm{mg}$ gallic acid equivalent (GAE)/g extract and $72.8 \pm 1.5 \mathrm{mg}$ catechin equivalent (CE)/g extract, respectively. The HPLC chromatogram at $280 \mathrm{~nm}$ (Fig. 1a-c) showed that chlorogenic acid was the predominant phenolic compound in FDLE at RT $=10.759$ which was calculated to $21.1 \pm 0.6 \mathrm{mg}$ chlorogenic acid (CGA)/g extract while unidentified peaks were observed at $\mathrm{RT}=5.092,8.264$ and 11.180 , respectively.

Table 1 Total amounts of major phytochemicals in FDLE

\begin{tabular}{|ll|}
\hline Phytochemicals & Total amounts (mg/g FDLE) \\
\hline Total phenolic content (mg GAE) & $341.6 \pm 5.4$ \\
\hline Total flavonoid content (mg CE) & $72.8 \pm 1.5$ \\
\hline Chlorogenic acid (mg CGA) & $21.1 \pm 0.6$ \\
\hline
\end{tabular}

\section{Effect of FDLE on aberrant crypt foci (ACF) formation in initiation stage}

During the entire experiment (Fig. 2a and 2b), the death of rats, differences of body weight and increasing level of serum ALT and AST in both initiation stage and post-initiation stage were not observed (Supplementary Table S1). The number and size of aberrant crypt foci (ACF) in experimental rats are presented in Table 2. All rats treated with DMH exhibited ACF that was distributed throughout the colon (Gr.2-4), while no ACF was observed in the NSS-treated group (Gr.1 and Gr.5). The total numbers of ACF observed in the DMH-treated group (Gr.2) accounted for $241 \pm 69$ (5.8\% inhibition) ACF/rat. Interestingly, only administration with FDLE at dose of $500 \mathrm{mg} / \mathrm{kg}$ bw (Gr.4) significantly decreased the total number of ACF/per rat to $151 \pm 41$ (37.3\% inhibition), when compared with a group of DMH-treated alone (Gr.2). Then, the mechanistic effect of FDLE on mutagenicity of colonic epithelial cell was investigated in the initiation stage.

Table 2 The number of ACF in DMH-treated rats with and without FDLE administration in initiation stage 


\begin{tabular}{|c|c|c|c|c|c|}
\hline \multirow[b]{2}{*}{ Treatment } & \multicolumn{4}{|c|}{ Number of $A C F /$ rat $^{a}$} & \multirow{2}{*}{$\begin{array}{l}\text { Aberrant } \\
\text { crypt/focus }\end{array}$} \\
\hline & Proximal & Distal & Rectal & $\begin{array}{l}\text { Total colon (\% } \\
\text { inhibition) }\end{array}$ & \\
\hline NSS(Gr.1) & $0 \pm 0$ & $0 \pm 0$ & $0 \pm 0$ & $0 \pm 0$ & $0 \pm 0$ \\
\hline $\mathrm{DMH}(\mathrm{Gr} .2)$ & $115 \pm 30$ & $100 \pm 32$ & $26 \pm 10$ & $241 \pm 69$ & $1.6 \pm 0.1$ \\
\hline $\begin{array}{l}\mathrm{DMH}+100 \mathrm{mg} / \mathrm{kg} \text { bw } \\
\operatorname{FDLE}(\mathrm{Gr} .3)\end{array}$ & $117 \pm 29$ & $93 \pm 26$ & $18 \pm 9$ & $227 \pm 58(5.8 \%)$ & $1.5 \pm 0.1$ \\
\hline $\begin{array}{l}\mathrm{DMH}+500 \mathrm{mg} / \mathrm{kg} \mathrm{bw} \\
\text { FDLE(Gr.4) }\end{array}$ & $70 \pm 24^{*}$ & $57 \pm 15^{\star}$ & $23 \pm 10$ & $151 \pm 41^{*}(37.3 \%)$ & $1.7 \pm 0.1$ \\
\hline $\begin{array}{l}\text { NSS+500mg/kg bw FDLE } \\
\text { (Gr.5) }\end{array}$ & $0 \pm 0$ & $0 \pm 0$ & $0 \pm 0$ & $0 \pm 0$ & $0 \pm 0$ \\
\hline
\end{tabular}

${ }^{a}$ Mean $\pm S D$ of 6 rats per group, ${ }^{*} p<0.05$; Significantly different from $\mathrm{Gr} .2$

\section{Effect of FDLE on DNA adduct and phase I \& II xenobiotic metabolizing enzymes activities in initiation stage}

During DMH metabolism, DNA methylation at the guanine $0^{6}$ site $\left(0^{6}-\mathrm{MeG}\right)$ was commonly observed in rat liver and colonic epithelial cells (Fig 3a). The concentration of $0^{6}-\mathrm{MeG}$ was determined 12 hours after the second $\mathrm{DMH}$ injection in experimental rats and is presented in Fig. 3b. The $0^{6}-\mathrm{MeG}$ level of $\mathrm{DMH}-$ treated rats (Gr.2) had significantly increased, when compared to the NSS-treated rats (Gr.1), in both liver tissue and colonic mucosa. In terms of FDLE-treated groups, administration at 100 and $500 \mathrm{mg} / \mathrm{kg} \mathrm{bw}$ in DMH-treated rats (Gr.3 and 4), both significantly reduced the level of $0^{6}-\mathrm{MeG}$ in both liver tissue and colonic mucosa, when compared to rats only treated with $\mathrm{DMH}(\mathrm{Gr} .2)$, while no significant change in this number was observed in both FDLE alone and the control group.

According to a reduction of DNA methylation by MAM, the effect of FDLE on MAM generation, including activities of hepatic DMH metabolizing enzyme, CYP2E1, UDPGT and GST were determined. Figures 3c, $3 \mathrm{~d}$ and 3 e illustrated the activities of CYP2E1, UDPGT, and GST, respectively. When the DMH-treated group (Gr.2) was compared to the NSS-treated group (Gr.1), the activity of CYP2E1-catalized hydroxylation was dramatically increased. FDLE administration at 100 and $500 \mathrm{mg} / \mathrm{kg}$ bw in DMHtreated rats (Gr.3 and 4) all significantly reduced this activity, when compared to rats only treated with DMH (Gr.2). Additionally, the activity of UDPGT and GST were also significantly increased in DMHinjected rats (Gr.2) in the response of reactive intermediates from phase I activity. For UDPGT, FDLE administration both 100 and $500 \mathrm{mg} / \mathrm{kg}$ bw in DMH-treated rats significantly reduced the activity, when compared to rats only treated with DMH (Gr.2), whereas only FDLE at $500 \mathrm{mg} / \mathrm{kg}$ bw was able to significantly reduce GST activity. In addition, PFLE treatment alone (Gr.5) had no effect on determined xenobiotic metabolizing enzymes. These results indicated that the reduction of phase I CYP2E1 activity decreased the generation of reactive intermediate MAM and the reduction of phase II UDPGT and GST 
activity decreased the production of MAM conjugate, which may cause the reduction of DNA adduct levels in the liver.

\section{Effect of FDLE on rat fecal bacterial $\beta$-glucuronidase activity in initiation stage}

In the colon, MAM conjugates are hydrolyzed to free MAM by intestinal bacterial $\beta$-glucuronidase enzymes, especially $0^{6}$-methylguanine $\left(0^{6}-\mathrm{MeG}\right)$, resulting in mutagenesis and thus tumorigenesis ${ }^{17}$; the activity of fecal bacterial $\beta$-glucuronidase before and after DMH injection are shown in Fig. 3f. The fecal $\beta$-glucuronidase activity in each group of rats was not different before $\mathrm{DMH}$ injection. After $\mathrm{DMH}$ injection, rat feces of the DMH-treated group (Gr.2) exhibited significantly higher $\beta$-glucuronidase activity $(54.5 \%)$ compared to the NSS-treated group (Gr.1). In terms of FDLE administration, fecal $\beta$-glucuronidase activity in $500 \mathrm{mg} / \mathrm{kg}$ bw with DMH-treated group (Gr.4) significantly declined, when compared to that of the rats only treated with $\mathrm{DMH}(\mathrm{Gr} .2)$. Looking at the similarities between patterns of $2^{\text {nd }}$ before and after DMH injection, FDLE administration at doses of 100 and $500 \mathrm{mg} / \mathrm{kg} \mathrm{bw} \mathrm{(Gr.3} \mathrm{and} \mathrm{4),} \mathrm{both} \mathrm{of} \mathrm{which}$ significantly decreased fecal $\beta$-glucuronidase activity compared to that of the $\mathrm{DMH}$-treated alone group (Gr.2). However, only FDLE administration (Gr.5) had no effect on fecal $\beta$-glucuronidase activity, compared to the untreated group (Gr.1) in different times. The results revealed that inhibiting fecal bacterial $\beta$-glucuronidase by FDLE may result in similar effect in the liver by ultimately decreasing the level of MAM, as well as the level of DNA adducts and ACF formation in the colon. Subsequently, the effect of FDLE on the kinetics of $\beta$-glucuronidase inhibition in $E$. coliwas investigated.

The kinetics of $E$. coli $\beta$-glucuronidase inhibition by FDLE were analyzed and Lineweaver-Burk plots were drawn as shown in Fig. $3 \mathrm{~g}$. In comparison to the untreated group, FDLE had no effect on the E. coli $\beta$ glucuronidase $\mathrm{V}_{\max }$, whereas all dosages of FDLE treatments increased the $\mathrm{K}_{\mathrm{m}}$ values of $E$. coli $\beta$ glucuronidase in a dose-dependent manner. The results suggested that the FDLE was a competitive inhibitor against $\beta$-glucuronidase activity. These findings demonstrated that the lowering of DMH-induced $0^{6}-\mathrm{MeG}$ DNA adduct formation in the colon was related to the regeneration of reactive intermediate MAM by bacterial $\beta$-glucuronidase. Therefore, FDLE could alter the DNA mutations and the formation of precancerous lesions during the initiation stage of colorectal carcinogenesis.

\section{Effect of FDLE on aberrant crypt foci (ACF) progression in post-initiation stage}

The number of ACF and crypt multiplicity (aberrant crypt/focus) in each part of the large intestine were presented in Table 3. The total number of ACF and average crypt multiplicity were observed in the DMHtreated group (Gr.2): about $354 \pm 52 \mathrm{ACF} /$ rat and $2.4 \pm 0.2 \mathrm{AC} /$ focus. Interestingly, administration with FDLE at doses of 100 and $500 \mathrm{mg} / \mathrm{kg}$ bw (Gr.3 and 4) significantly decreased the total number of ACF/rat to $239 \pm 53$ (32.5\% inhibition) and $184 \pm 63$ (48.0\% inhibition), when compared to rats only treated with $\mathrm{DMH}$ (Gr.2). Administration with FDLE at dose of 100 and $500 \mathrm{mg} / \mathrm{kg}$ bw (Gr.3 and 4) also significantly decreased the average crypt multiplicity to $2.0 \pm 0.2$ (16.7\% inhibition) and $1.9 \pm 0.1$ (18.4\% inhibition) when compared with DMH-treated group alone (Gr.2). Afterwards, the mechanistic effect of FDLE on 
inflammation, cell proliferation and apoptosis related to ACF progression were investigated in the postinitiation stage.

Table 3 The number of ACF and AC/F in DMH-treated rats with and without FDLE administration in postinitiation stage

\begin{tabular}{|c|c|c|c|c|c|}
\hline \multirow[b]{2}{*}{ Treatment } & \multicolumn{4}{|c|}{ Number of $\mathrm{ACF} / \mathrm{rat}^{\mathrm{a}}$} & \multirow{2}{*}{$\begin{array}{l}\text { Aberrant } \\
\text { crypt/focus } \\
\text { (\%inhibition) }\end{array}$} \\
\hline & Proximal & Distal & Rectal & $\begin{array}{l}\text { Total colon } \\
\text { (\% inhibition) }\end{array}$ & \\
\hline NSS(Gr.1) & $0 \pm 0$ & $0 \pm 0$ & $0 \pm 0$ & $0 \pm 0$ & $0 \pm 0$ \\
\hline $\mathrm{DMH}(\mathrm{Gr} .2)$ & $136 \pm 26$ & $175 \pm 33$ & $43 \pm 15$ & $354 \pm 52$ & $2.4 \pm 0.2$ \\
\hline $\begin{array}{l}\text { DMH+100mg } / \mathrm{kg} \text { bw } \\
\text { FDLE(Gr.3) }\end{array}$ & $97 \pm 28^{* \star}$ & $125 \pm 39^{* \star}$ & $17 \pm 12^{\star \star \star \star}$ & $\begin{array}{l}239 \pm 53^{\star \star \star \star} \\
(32.5 \%)\end{array}$ & $2.0 \pm 0.2^{\star \star \star \star}(16.7 \%)$ \\
\hline $\begin{array}{l}\text { DMH+500mg/kg bw } \\
\text { FDLE(Gr.4) }\end{array}$ & $73 \pm 33^{\star \star \star \star}$ & $96 \pm 30^{\star \star \star \star}$ & $15 \pm 13^{\star \star \star \star}$ & $\begin{array}{l}184 \pm 63^{\star \star \star \star} \\
(48.0 \%)\end{array}$ & $1.9 \pm 0.1^{\star \star \star \star}(18.4 \%)$ \\
\hline $\begin{array}{l}\text { NSS+500mg/kg bw } \\
\text { FDLE (Gr.5) }\end{array}$ & $0 \pm 0$ & $0 \pm 0$ & $0 \pm 0$ & $0 \pm 0$ & $0 \pm 0$ \\
\hline
\end{tabular}

a Mean \pm SD of 10 rats per group, ${ }^{*} p<0.05,{ }^{* *} p<0.01,{ }^{* \star *} p<0.001,{ }^{* \star \star *} p<0.0001$, Significantly different from Gr.2

\section{Effects of FDLE on inflammation in rat colonic mucosal cells}

Inflammation plays a vital role in mechanism of cancer development ${ }^{18}$. Firstly, the mRNA levels of proinflammatory cytokines and enzymes in rat colonic epithelial cells were determined, as shown in Fig. 4a. The relative expression of IL-1 $\beta$, IL-6, TNF- $\alpha$, iNOS and COX-2 in DMH treatment (Gr.2) were significantly upregulated, compared to NSS-treated rats (Gr.1). Administration with FDLE only at a dose of $500 \mathrm{mg} / \mathrm{kg}$ bw (Gr. 4) to DMH-treated rats were able to significantly suppress the expression of IL-1 $\beta$, IL-6 when, while both doses at 100 and $500 \mathrm{mg} / \mathrm{kg}$ bw of FDLE (Gr.3-4) were found to considerably suppress the expression of TNF-a, iNOS and COX-2, when compared with DMH-treated rats (Gr.2). Administration with FDLE (Gr.5) had no effect on the expression of these genes. The results suggested that FDLE could reduce the rat colonic inflammation determined by the downregulation of IL-1 $\beta, I L-6, T N F-a, C O X-2$ and iNOS genes expression. However, the scraped colonic mucus layer was composed of both activated immune cells and colonic epithelial cells, the inflammatory responses in the colon cancer cell line and activated macrophage were confirmedly determined in vitro.

\section{Effects of FDLE on inflammatory responses in cell lines}

To elucidate the inhibitory effect on microenvironments rich in inflammatory cells by using LPS-activated RAW 264.7 cells, the level of pro-inflammatory cytokines TNF-a, IL-1 $\beta$ and IL- 6 were measured, as shown 
in Fig. 4b. LPS increased TNF-, IL-1, and IL-6 secretion, relative to the control group, but were not compared to FDLE alone. While FDLE significantly reduced TNF- and IL-1 secretion but had no effect on IL-6 secretion compared to LPS alone. This data assumed that FDLE could reduce inflammation in macrophage induced by bacterial lipopolysaccharide.

To investigate whether FDLE could modulate the response of human colorectal cancer cell lines to mixtures of TNF- $a$, IFN- $y$ and LPS, the mRNA expression of TNF- $a$, IL-1 $\beta$ and IL- 6 in HT-29 and HCT-116 in human colorectal cancer cell lines treated by a combination of cytokines was then measured and shown in Fig. 4c and 4d. After 48 hours of treatment with a cytokine mixture, TNF-, IL-1, and IL-6 relative mRNA increased in HT-29 and HCT-116 colorectal cancer cells, compared to the negative control. FDLE reduced both TNF- and IL-1 expression in HT-29 cells, and TNF-, IL-1, and IL-6 expression in HCT-116 cells. The results indicated that FDLE also inhibited the responsibility of colorectal cancer cell lines to inflammatory cytokines from inflammation, which might be related to the growth promotion of aberrant colonic cells.

\section{Effects of FDLE on cell proliferation and apoptosis of rat colonic mucosa in post-initiation stage}

Inflammation plays a critical role in the neoplastic process by promoting proliferation and survival which inhibits apoptosis induction ${ }^{19}$. The protein expression related to cell proliferation and apoptosis in colonic mucosal cells was shown in the Fig. 5a, 5b and 5c. PCNA, cell proliferation marker protein, considerably higher in the DMH-treated group (Gr.2) compared to the NSS-treated group (Gr.1). FDLE at 100 and $500 \mathrm{mg} / \mathrm{kg}$ bw reduced the expression of PCNA protein in DMH-treated rats (Gr.3 and 4) compared to $\mathrm{DMH}$ alone (Gr.2). Furthermore, DMH administration retarded colonic epithelial cell apoptosis observed by reducing cleavage caspase-3 level, compared to NSS treatment (Gr.1). FDLE at 100 and $500 \mathrm{mg} / \mathrm{kg}$ bw significantly increased the level of cleaved caspase-3 protein in DMH-treated rats (Gr.3 and 4) compared to DMH alone (Gr.2). Likewise, rats only treated with FDLE (Gr.5) had no effect on the level of PCNA or cleaved caspase-3 proteins. These results confirmed that FDLE was able to inhibit cell proliferation and promote cell apoptosis in hyperproliferative colonic epithelial cells.

\section{Effects of FDLE on cell proliferation of HT-29 and HCT-116 colorectal cancer cell lines induced by pro- inflammatory cytokines}

To investigate the effect of FDLE on the growth of the HT-29 and HCT-116 colorectal cancer cell lines in an inflammatory environment, we examined FDLE's anti-proliferation activity against cytokine-induced HT-29 and HCT-116. As shown in Fig. 5d and 5e, treatment with cytokines resulted in a considerable increase in the relative cell number of HT-29 and HCT-116 at 48 hours, when compared to the negative control. After 48 hours, FDLE administration considerably decreased cytokine-induced HT-29 and HCT-116 cell proliferation, compared to the positive control; at the same time, a high dose of FDLE administration dramatically decreased cytokine-induced HT-29 and HCT-116 cell proliferation, compared to the negative control. Cytokines were found to enhance cell proliferation, whereas FDLE inhibited cell proliferation in both inflamed and non-inflamed HT-29 and HCT-116 colorectal cancer cell lines. 


\section{Discussion}

Ficus species are a rich source of polyphenolic compounds and flavonoids, which are responsible for antioxidant, anti-inflammation and anti-proliferation properties that help in the prevention and therapy of various diseases ${ }^{20-22}$. The biological composition and function of Ficus dubia as a new Ficus species have not been studied on its which should have greater research value. Our experiment found that FDLE contains a high number of phenolic acids (34.2\%) and flavonoids (7.3\%), especially, the amount of chlorogenic acid as one type of phenolic is about $2.1 \%$. With an extraction yield of $7.67 \%$ in the previous study ${ }^{11}$; in our investigation, the chlorogenic acid accounted for $161.84 \mathrm{mg}$ per gram of latex as well as a comparable quantity of total phenolic content. Additionally, the aforementioned study provides similar results for quinic acid, a metabolite form of chlorogenic acid. The remaining phenolic acids detected in FDLE require further investigation to determine their identity. In terms of other Ficus species, especially $F$. carica, the most common phenolic chemicals were chlorogenic acid, followed by rutin despite the plant's extraction from other parts ${ }^{23-25}$. Apart from chlorogenic acid and its derivative compounds, quinic acid exhibited anticancer effects in HT-29 human colorectal cancer cells in vitro and xenograft models, whereas chlorogenic acid increased ROS generation and decreased cell viability in human colorectal cancer cells ${ }^{26,27}$. As a result, FDLE has the potential to be used as a functional natural substance to aid in the prevention of various carcinogenesis, such as liver and prostate cancer ${ }^{28}$. However, there is a lack of studies on FDLE's chemopreventive efficacy against DMH-induced colorectal carcinogenesis.

Based on the multi-step process involved in colorectal carcinogenesis, the transformation of normal crypts to aberrant crypt foci (ACF) is a hallmark of DMH-induced colorectal carcinogenesis that has been used in a variety of studies to evaluate the extract's effects ${ }^{4}$. As an intermediate marker, ACF has been utilized to identify and evaluate the preventative effects in the early stages of colorectal carcinogenesis ${ }^{29}$. Earlier evidence suggested that the bioactive compounds which inhibit ACF could also promote the anticarcinogenicity of carcinogen-induced colorectal cancer models ${ }^{30-32}$. In our study, no adverse effects were found in the rats only treated with FDLE throughout an eight-week period, indicating that FDLE had no toxicity, as shown in supplementary Table S1. The formation of ACF is mainly reflected in the appearance of small crypt multiplicity, which shows that colorectal cancer is starting to be initiated. However, the progression of ACF is manifested in the transformation of small crypt multiplicity into large crypt multiplicity, which shows the progression of colorectal cancer ${ }^{33}$. Our results demonstrated that FDLE treatment diminished not only the total number of ACF, but also the size of crypts, particularly those with a large crypt multiplicity, defined as more than three crypts/foci. Therefore, it could be firstly summarized that FDLE suppressed ACF formation at the initiation stage of DMH-induced colorectal carcinogenesis and prevented ACF progression during the post-initiation stage.

In terms of DMH-induced ACF formation, xenobiotic-metabolizing enzymes, including phase I in the liver, namely CYP2E1, activate DMH to form methylazoxymethanol (MAM), an electrophilic methylating agent of nucleic acid that interacts with DNA, resulting in DNA adduction at $0^{6}$-methylguanine $\left(0^{6}-\mathrm{MeG}\right)$ and $\mathrm{N}^{7}$ methylguanine ( $\left.\mathrm{N}^{7}-\mathrm{MeG}\right)$ and then, ultimately, occur mutagenesis and tumorigenesis ${ }^{17,34}$. Therefore, 
reducing phase I enzyme activity is considered to be an effective strategy to prevent DNA adduct formation by reactive intermediates in the early stage ${ }^{34-36}$. This experiment found that $\mathrm{DMH}$ administration significantly increased the activities of CYP2E1 enzymes subsequently increased the level of $0^{6}-\mathrm{MeG}$ DNA adduct in the liver, whereas the administration with FDLE significantly reduced these effects (Fig. 3b and 3c). Apart from phase I enzymes, UDPGT and GST are the determined phase II detoxifying enzymes that increase the water solubility and decrease the toxicity of a variety of xenobiotic substrates by conjugation with glucuronic $\operatorname{acid}^{37}$. Unfortunately, FDLE, however, did not increase the activity of phase II enzymes in our investigations (Fig. 3d and 3e). The activities of these phase II enzymes were decreased which responded to the inhibition of phase I enzyme. Consequently, the data indicated that FDLE decreases DNA adducts primarily by inhibiting the activity of phase I enzyme which relates to the formation of reactive intermediate MAM, leading to reduced transportation of MAMconjugate via the bile system.

In colon lumen ${ }^{38}$, intestinal bacterial $\beta$-glucuronidase hydrolyzes the conjugated MAM to release free MAM. After it is reabsorbed to colonic epithelial cell, the colon carcinogenesis is proceeded by DNA adduct and mutation ${ }^{39}$. Therefore, reducing bacterial $\beta$-glucuronidase activity is an effective strategy to minimize DNA adduct levels, as well as prevent colorectal carcinogenesis ${ }^{35,40}$. In this study, administration with FDLE significantly reduced the activity of bacterial $\beta$-glucuronidase induced by DMH in the rat colon (Fig. 3f) and FDLE was confirmed to be a competitive inhibitor against purified E.coli $\beta$ glucuronidase (Fig. $3 \mathrm{~g}$ ). Therefore, administration with FDLE significantly reduced the colon $0^{6}$-MeG DNA adduct by lowering free MAM from bacterial enzyme hydrolysis. From all the mentioned results, it can be concluded that FDLE inhibited DMH-induced colorectal carcinogenesis through the alteration of xenobiotic metabolizing processes in both the liver and colon, which causes the reduction of DNA adduct levels and ACF numbers in the initiation stage. Chlorogenic acid is an active compound in PDLE which we expected to be an anti-carcinogenic agent in this model. It has been also reported that chlorogenic acid, an active component in FDLE, exhibits the inhibition of ACF formation in rat-received azoxymethane (AOM) by affecting the AKT/mTOR pathway ${ }^{41,42}$. Therefore, the well-known effect of chlorogenic acid has been used to compare the effects of FDLE in this study.

Turning to the post-initiation stage, the DMH-induced initiated cells were capable of developing into premalignant tumors as a result of their hyperproliferation and apoptotic resistance which needed to be inhibited in colorectal cancer cells. DMH was administered to rats before FDLE treatment in the postinitiation model to determine its suppressive activities on ACF progression ${ }^{4}$. Due to the difference in ACF progression time, the amount of DMH-induced ACF formations in the post-initiation stage $(354 \pm 52$

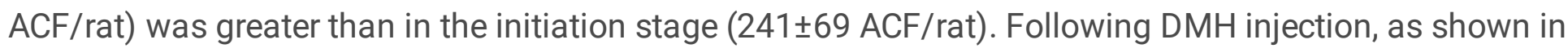
Table 3, FDLE administration significantly decreased the number of colonic ACF, accounting for $32 \%$ and $48 \%$ at doses of 100 and $500 \mathrm{mg} / \mathrm{kg}$ bw, respectively. Similarly, the percentage inhibition of ACF formation in the post-initiation model indicated that FDLE was more suppressed than in the initiation model, indicating that additional in-depth investigation of the mechanism would be more interesting. 
Beyond the anti-cancer activities of FDLE in the post-initiation model, it has been established that inflammation promotes tumor progression and pro-inflammatory cytokines such as TNF-, IL-6, and IL-1, as well as pro-inflammatory enzymes such as iNOS and COX-2, all of which can cooperate to regulate colorectal cancer-associated pathophysiological processes such as cell proliferation and survival, differentiation, immunity, metabolism and metastatic behavior ${ }^{43,44}$. According to certain research, DMH increased the expression of these inflammatory cytokines during DMH-induced colorectal carcinogenesis; hence, inhibition of inflammation using certain active substances serves as an effective approach to prevent and treat colorectal cancer ${ }^{43,45,46}$. Our experiment also found DMH significantly increased the inflammatory response, while treatment with FDLE markedly decreased the mRNA expression levels of TNF-a, IL-6, IL-1 $\beta$, iNOS and COX-2 in rat colonic mucosa, substantiating their inhibitory action towards inflammation-associated colorectal tumor progression (Fig. 4a). In addition, the anti-inflammation of FDLE on macrophages, the main cell of inflammatory response, was also analyzed. FDLE significantly decreased LPS-induced secretion of pro-inflammatory cytokines TNF- $\alpha$ and IL-1 $\beta$ from macrophages (Fig. 4b). Simultaneously, the ability of inflammation to promote cell proliferation was examined in vitro. Our data showed that mixed cytokines could induce inflammatory responses in HT-29 and HCT-116 colorectal cancer cell lines (Fig. 4c and 4d), which could promote these cancer proliferations (Fig. 5D and $5 E)$. It could be demonstrated that inflammation and an inflammatory microenvironment could continue to promote cell inflammation and proliferation ${ }^{47}$. Interestingly, FDLE suppressed the expression of proinflammatory cytokines and enzymes induced by carcinogens or inflammatory inducers, which could establish their anti-inflammatory and anti-proliferative potential. Our experimental findings support the concept that inhibitors of one or some of these inducible pro-inflammatory cytokines and proinflammatory enzymes are potential chemopreventive agents against colorectal carcinogenesis in preclinical models ${ }^{48}$. In the same way, chlorogenic acid has also been reported as having the ability to decrease the inflammatory response by decreasing TNF-alpha and COX-2 levels ${ }^{49}$.

The balance of cell proliferation and apoptosis is critical for the intestinal mucosa's integrity, and dysregulation of tumor cell proliferation and apoptosis frequently results in hyperplasia and carcinogenesis $2,45,50$. Therefore, inhibiting cell proliferation and inducing cell apoptosis are considered to be effective strategies for the prevention and treatment of cancer ${ }^{10}$. In this experiment DMH dramatically raised nuclear availability of PCNA protein, a marker of DNA replication, while also causing hyperplasia and dysplasia in DMH-induced rat colonic mucosa (Supplementary Fig. S1), indicating increased cellular proliferation in colonic epithelial tissue. Administration with FDLE significantly decreased the expression of PCNA protein (Fig. 5a and b). In addition, an alteration of histopathological appearance of cell hyperproliferation such as hyperplasia and dysplasia were observed in rats received FDLE. (Supplementary Fig. S1). In addition, in vivo studies were comparable to those conducted in vitro, especially cell proliferation assays in response to combinations of cytokine and FDLE treatments (Fig. $5 \mathrm{~d}$ and 5e). In terms of apoptosis, DMH dramatically reduced the activation of caspase-3, but an increase of cleaved caspase 3 was observed following FDLE administration, demonstrating that FDLE may enhance cell apoptosis (Fig. 5a and 5d). Moreover, these effects are most likely the result of chlorogenic acid that suppresses cell proliferation and induces apoptosis ${ }^{42,51}$. When combined with the results of previous 
inflammation and ACF in vivo and in vitro experiments, these data clearly demonstrated that FDLE inhibited the multiplicity of ACF by controlling inflammation, which leads to decreased cell proliferation and induces cell apoptosis in the post-initiation stage and this plant will be value-added further in the future.

\section{Conclusion}

The experimental findings of our study indicate that administration of FDLE effectively prevent DMH induced colorectal carcinogenesis by the inhibition of ACF formation and progression. FDLE inhibits ACF formation by reducing xenobiotic metabolizing enzymes activities in the liver and reducing $\beta$ glucuronidase activity in the colon, leading to both reduced formation of DNA adducts and the number of $A C F$, in the initiation stage. FDLE inhibits ACF progression by reducing inflammation, leading to decreased cell proliferation and increased cell apoptosis which caused a decrease of ACF numbers and crypt multiplicity in the post-initiation stage. Therefore, the latex of Ficus dubia has the potential to be a chemopreventive agent for colorectal diseases. The molecular mechanisms and the applications should be further investigated. A summary of chemopreventive mechanism of FDLE in DMH-induced rat colorectal carcinogenesis is shown in Fig. 6.

\section{Materials And Methods}

All methods in these studies were performed in accordance with the relevant guidelines and regulations. In addition, the animal protocol has been proved by the Faculty of Medicine, Chiang Mai University, Thailand (code: 04/2562). We confirmed that all data were reported in accordance with ARRIVE guidelines.

\subsection{Chemicals}

The carcinogen 1, 2-dimethylhydrazine (DMH) was obtained from Tokyo Chemical Industry. P-nitrophenyl$\beta$-D-glucuronide, E coli $\beta$-glucuronidase, glutathione, uridine diphosphate glucuronic acid (UDPGA), 1chloro-2,4dinitro benzene (CDNB), glycogen, guanine and $0^{6}-\mathrm{MeG}$ were purchased from Sigma-Aldrich Chemical Co. Tris- $\mathrm{HCl}$ and sucrose were obtained from Thermo Fisher Scientific Inc. Phenol-chloroformisoamylalcohol was obtained from Research Organics Inc. Other reagent grade chemicals were obtained from Merck Millipore Bioscience (Thailand).

\subsection{The extraction and preparation of Ficus dubia latex}

Ficus dubia latex was collected and identified by Bhanumas Chantarasuwan, National Science Museum, Thailand (voucher number: Chantarasuwan 040117-1) and extract was conducted and provided by the Institute of Nutrition, Mahidol University as described in previous study ${ }^{11}$ The powder of Ficus dubia latex was soaked with deionized water at the ratio of $1: 10 \mathrm{w} / \mathrm{v}$. The aqueous fraction was filtrated and freezedried. The crude extract powder of Ficus dubia latex (FDLE) was kept at $-20^{\circ} \mathrm{C}$ for further experiments. FDLE was dissolved in deionized water just before use. 


\subsection{Measurement of total phenolic and flavonoid contents}

The total phenolic contents were determined by Folin-Ciocaiteu assay, as described in Song FL, et al. ${ }^{52}$ The total phenolic contents were calculated and expressed as gallic acid equivalents (GAE) in mg/g extract, by comparison with the standard calibration curve of gallic acid. The total flavonoid contents were determined by aluminum chloride colorimetric method. The assay was performed according to the method of Subedi L, et al. ${ }^{53}$ The total flavonoid contents were calculated and expressed as catechin equivalents (CE) in $\mathrm{mg} / \mathrm{g}$ extract by comparison with the standard calibration curve of catechin.

\subsection{Measurement of known phenolic and flavonoid concentration}

The phenolic and flavonoid fingerprint of FDLE were determined by HPLC, according to the method of Shao, Y., Xu, F., Sun, X., Bao, J. \& Beta, T. ${ }^{54}$ The extract was determined for the existence of phytochemical contents by HPLC using a C18 column $(250 \times 4.6 \mathrm{~mm}, 5 \mu \mathrm{m})$ (Agilent Technologies, Santa Clara, CA, USA). The chromatographic separation was carried out using the isocratic mode of mobile phase $\mathrm{A}$ ( $1 \%$ acetic acid in water) and mobile phase $B(100 \%$ acetonitrile) with a total run time of 50 min for detection with a flow rate of $0.7 \mathrm{~mL} / \mathrm{min}$. The gradient system used was $90 \% \mathrm{~A}$ in $0 \mathrm{~min}-60 \%$ in $28 \mathrm{~min}$, followed by $40 \%$ in the next $39 \mathrm{~min}$ and $10 \%$ in the next $50 \mathrm{~min}$. The extract of $10 \mathrm{mg} / \mathrm{mL}$ dissolved in $1 \mathrm{~mL}$ of $\mathrm{MeOH}$ was injected into the column and phytochemical contents at $280 \mathrm{~nm}$ were detected. The peak area and retention time of the extract sample were evaluated as the comparison with the standard curve (apigenin and chlorogenic acid).

\subsection{Animals model and protocol approving}

The male Wistar rats (four-five weeks of age, weighing 80-100-grams) used in this study were purchased from Nomura Siam International, Thailand. Rats were housed in cages in an air-conditioned room (25$30^{\circ} \mathrm{C}$ ) with exposure to 12/12-hours light/dark cycle. The animal treatment protocol was approved by the Animal Ethics Committee, Faculty of Medicine, Chiang Mai University, Thailand (code: 04/2562).

\subsection{Colorectal cancer induction and experimental protocol and treatment schedule}

\section{Initiation protocol}

Rats were divided into five groups (10 rats each). The control groups (groups 1 and 5) received a normal diet (negative control) and only a high dose of FDLE (treatment control) with $0.9 \%$ normal saline solution injection, respectively. In the experimental groups, positive control (group 2) rats received a normal diet. Rats in group 3 and 4 received FDLE of 100 and $500 \mathrm{mg} / \mathrm{kg}$ bodyweight, respectively, for one week before the first injection of DMH and continued for 5 weeks. All experimental rats were injected with DMH (40 $\mathrm{mg} / \mathrm{kg}$ of body weight), subcutaneously, once a week at weeks 1 and 2 . Feces of rats from each group were directly collected for $\beta$-glucuronidase activity measurement. Twelve hours after the second DMH injection (two weeks), five rats of each group were sacrificed using Zoletil 100, a combination of tiletamine and zolazepam, at $20 \mathrm{mg} / \mathrm{kg}$ of body weight. The liver and colon were collected for xenobiotic 
metabolism enzyme activity and DNA adduct determination. After five weeks, the remaining six rats were sacrificed, then the colon was collected and processed for ACF determination according to Bird et. al. ${ }^{55}$, serum was used for measurement of ALT and AST for liver function.

\section{Post-initiation protocol}

The grouping was the same as the initiation stage with 14 rats/group, FDLE were treated after two weeks of the second DMH injection for a further four weeks. After the rats were sacrificed, colons from six rats were fixed for determination of ACF and those from the other four rats were frozen for mRNA and protein extraction. The toxicity of FDLE was evaluated by rat body weight and serum transaminase activity, SGOT and SGPT.

\subsection{Aberrant crypt foci (ACF) analysis}

Rat colons were removed and fixed in 10\% formalin-phosphate-buffer saline (PBS) solution (pH 7.4) by initial cutting the rectum ( $2 \mathrm{~cm}$ from the anus) followed by the proximal and distal convoluted tubule halving of the colon. Fixed colons were stained with $0.2 \%$ blue methylene, then the ACF were scored under a light microscope at a magnification of $10 \mathrm{X}$. The number of $\mathrm{ACF} /$ rat and $\mathrm{AC} /$ focus were analyzed according to Bird et. al. ${ }^{55}$

\subsection{Measurement of phase I and phase II xenobiotic metabolic enzymes activity}

Liver tissues were extracted cytosolic and microsomal protein by centrifugal sedimentation ${ }^{32}$. The procedure for microsomal cytochrome P4502E1 (CYP2E1)-catalyzed p-nitrophenol hydroxylation measurement was based on the method described by Chang et al., with some modifications ${ }^{56}$, the enzyme activity was calculated and expressed as micromole of product formed $/ \mathrm{min} / \mathrm{mg}$ protein. UDPGlucuronosyltransferase (UDPGT) activity measurement was done using p-nitrophenyl phosphate (PNP) as the substrate according to the modified method of Woodcock et al. ${ }^{57}$, while glutathione-S-transferase (GST) activity measurement was evaluated by monitoring the conjugation of 1-chloro-2,4-dinitro benzene (CDNB) with glutathione, according to the methods of Habig et al. ${ }^{58}$

\subsection{Measurement of fecal bacterial $\beta$-glucuronidase activity}

Fecal bacterial $\beta$-glucuronidase activity was measured using rat feces collected before and after the injections of DMH, using p-nitrophenyl phosphate (PNP) as the substrate, according to the modified method of Deeptha et al. ${ }^{59}$. The enzyme activity was calculated and expressed as $\mu \mathrm{mol} \mathrm{min}^{-1} / \mathrm{g}$ feces. To determine the kinetically inhibitory effect of FDLE E.coli $\beta$-glucuronidase, $5 \mu \mathrm{L}$ of $20 \mathrm{U} / \mathrm{mL}$ of E. coli $\beta$ -


EDTA with the $5 \mu \mathrm{L}$ of various concentration of FDLE and incubated at $37^{\circ} \mathrm{C}$ for $15 \mathrm{~min}$. The reaction was started by adding $5 \mu \mathrm{L}$ of 2 to $8 \mathrm{mM}$ of $p$-nitrophenyl- $\beta$-D-glucuronide (PNPG) substrate or distilled water (blank), then the reaction mixture was incubated at $37^{\circ} \mathrm{C}$ for $15 \mathrm{~min}$. After adding $200 \mu \mathrm{L}$ of $0.2 \mathrm{M}$ glycine buffer, $\mathrm{pH} 10.4$ in $0.2 \mathrm{M} \mathrm{NaCl}$, absorbance was measured at $450 \mathrm{~nm}$ to calculate the reaction velocity in 
the presence of each concentration of inhibitor (extract). The alteration of $\mathrm{K}_{\mathrm{m}}$ and $\mathrm{V}_{\mathrm{max}}$ were determined from double-reciprocal plot to define the inhibition type of FDLE against $\beta$-glucuronidase.

\subsection{Measurement of DNA adducts $0^{6}$-Methylguanine by HPLC}

The procedure for detection of DNA adducts was based on the method described by Iwitzki et al. ${ }^{60}$ Frozen liver and colon were defrosted on ice. Total DNA was isolated by phenol-chloroform and DNA in the

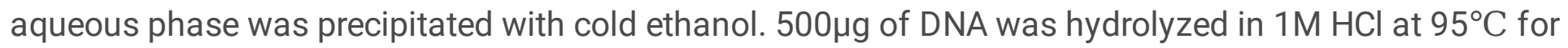
1 hour (acid hydrolysis). Diluted DNA hydrolysate was analyzed using an Agilent HPLC Column (PLSCX1000A $10250 \times 4.6 \mathrm{MM}$ ). The isocratic separation with buffer $A(10 \%$ methanol in $20 \mathrm{mM}$ ammonium formate, $\mathrm{pH} 4.0$ ) was carried out for 3 min then a linear gradient was applied ranging from buffer $A$ to $25 \%$ buffer $\mathrm{B}$ ( $5 \%$ methanol in $200 \mathrm{mM}$ ammonium formate, $\mathrm{pH} 4.0$ ) for $15 \mathrm{~min}$, followed by $25 \%$ buffer $\mathrm{B}$ for 2 minutes at a flow rate of $1.5 \mathrm{~mL} / \mathrm{min}$. The nucleotide bases were detected using a UV detector at $275 \mathrm{~nm}$. The amount of hydrolyzed DNA was quantified by the peak area of the guanine and $0^{6}$ methylguanine. The level of $\mathrm{O}^{6}$-methylguanine was calculated by using a standard curve and expressed as micromole of $0^{6}-\mathrm{MeG} / \mathrm{mole}$ of guanine.

\subsection{Determination of pro-inflammatory cytokines and enzymes mRNA expression by qPCR}

Total RNA from rat colonic mucosa was isolated using Trizol ${ }^{\circledR}$ reagent (AMBION, USA) following the manufacturer's instructions. The cDNA was synthesized from total RNA $(2 \mu \mathrm{g})$ using ReverTra Ace qPCR RT master mix (TOYOBO, Japan) in a $20 \mu$ reaction mixture carried out at $37^{\circ} \mathrm{C}$ for $15 \mathrm{~min}, 50^{\circ} \mathrm{C}$ for $5 \mathrm{~min}$, $98^{\circ} \mathrm{C}$ for $5 \mathrm{~min}$. PCR amplification performed with the maxima SYBR Green qPCR master mix (Thermo Fisher Scientific, USA), the reaction included at $95^{\circ} \mathrm{C}$ for $15 \mathrm{~min}, 95^{\circ} \mathrm{C}$ for $15 \mathrm{sec}, 60^{\circ} \mathrm{C}$ for $60 \mathrm{sec}$ for 40 cycles and the PCR-amplified gene products were analyzed. Level of mRNAs including TNF-a, IL-6, IL-1 $\beta$, COX-2 and iNOS were quantified with normalization to $\beta$-actin mRNA.

\subsection{Measurement of pro-inflammatory cytokine in culture supernatant by ELISA}

Firstly, RAW264.7 cells ( $5 \times 10^{5}$ cells) were cultured in a 6-well plate with $1 \mu \mathrm{g} / \mathrm{mL}$ lipopolysaccharide (LPS) for 24 hours. Then, the cells were washed with PBS and various concentrations of $\operatorname{PFLE}(50,100$ and $200 \mu \mathrm{g} / \mathrm{mL}$ ) were added for 24 hours. Finally, the culture supernatant was collected and used to determine the secreted inflammatory cytokines including TNF-a, IL-1 $\beta$ and IL- 6 with ELISA kit (Thermo Fisher Scientific, USA \& Canada) according to the manufacturer's instruction. Three independent experiments were performed with at least triplicate per experiment.

\subsection{Measurement of cell proliferation by MTT}

HT-29 and HCT-116 colon cancer cells $\left(1 \times 10^{4}\right.$ cells) were cultured in a 96-well plate with cytokines (TNFa, IFN- $\gamma$ and LPS at each $10 \mathrm{ng} / \mathrm{ml}$ ) for 24 hours, then, various concentrations of FDLE (50, 100 and 200 $\mu \mathrm{g} / \mathrm{mL}$ ) were added for 24 and 48 hours. At the indicated times, $15 \mu \mathrm{L}$ of $5 \mathrm{mg} / \mathrm{mL}$ MTT solution were added. The incubation was carried out at $37^{\circ} \mathrm{C}$ for four hours. All solution was discarded and a $100 \mu \mathrm{L}$ 
DMSO was added to dissolve formazan crystals. The violet solution was measured the absorbance at $540 / 630 \mathrm{~nm}$ by using microplate reader. A percentage of cell proliferation was calculated against vehicle treated cells. The experiments were repeated three times with at least triplicate per experiment.

\subsection{Measurement of PCNA and cleaved caspase-3 by Western blot}

Total proteins were collected after centrifugation of epithelial cell homogenate and SDS-polyacrylamide gel electrophoresis (PAGE) was used to separate denatured proteins and then transferred them onto nitrocellulose membrane. The transferred proteins were detected using specific primary anti-PCNA (1:2000), anti-cleaved caspase-3 (1:1000), anti- $\beta$-actin (1:5000) overnight at $4^{\circ} \mathrm{C}$ and secondary antirabbit (1:5000) were labeled with horse radish peroxidase enzyme followed by chemiluminescent substrate. The specific target proteins were visualized by adding Western lightening Chemiluminescent HRP Substrate (PerkinElmer, USA) and the pictures were captured by Kodak X-ray film. The intensity of the target proteins was measured by Image $J$ program. The relative expression was normalized against $\beta$ actin expression and then compared to the non-treatment group.

\subsection{Statistical analysis}

The values are given as the mean \pm SD. Significant differences between the means of the groups were analyzed by one way analysis of variance (ANOVA). The results were considered statistically significant at $P<0.05,{ }^{*} p<0.05,{ }^{\star *} p<0.01,{ }^{* \star *} p<0.001,{ }^{\star \star \star \star} p<0.0001$. All the image quantifications were done by Image-Pro (version 7.0). All the statistics were performed on Graphpad Prism 6.0 (GraphPad Software, USA).

\section{Declarations}

\section{Acknowledgements}

This work was financially supported by Agricultural Research Development Agency (Public Organization) (grant number: CRP610502213).

\section{Authors' contribution}

Teera Chewonarin has contributed considerably to the study conception and experimental design. Rentong Hu and Weerachai Chantana was responsible for experimental performing, data collecting, and analysis. Bhanumas Chantarasuwan, was responsible for sample collecting and identification. Piya Temviriyanukul and Pornsiri pitchakarn prepared materials and extracts with quality control. Rentong $\mathrm{Hu}$ and Subhawat Subhawa wrote the first draft of the manuscript, and all authors provided feedback on previous versions. Teera Chewonarin read and approved the submitted version. All authors have agreed both to be personally accountable for the author's own contributions and to ensure that questions related to the accuracy or integrity of any part of the work.

\section{Funding}


The Agricultural Research Development Agency (Public Organization), Thailand, grant number CRP610502213.

\section{Competing interests}

The authors declare that they have no conflicts of interest.

\section{References}

1. Okada, K. et al. Combination of the histone deacetylase inhibitor depsipeptide and 5-fluorouracil upregulates major histocompatibility complex class II and p21 genes and activates caspase-3/7 in human colon cancer HCT-116 cells. Oncology reports 36, 1875-1885 (2016).

2. Aranganathan, S. \& Nalini, N. Retracted: Antiproliferative Efficacy of Hesperetin (Citrus Flavanoid) in 1, 2-Dimethylhydrazine-Induced Colon Cancer. Phytotherapy Research 27, 999-1005 (2013).

3. Manju, V. \& Nalini, N. Effect of ginger on lipid peroxidation and antioxidant status in 1, 2-dimethyl hydrazine induced experimental colon carcinogenesis. Journal of Biochemical Technology 2,161167 (2010).

4. Khanaree, C., Pintha, K., Tantipaiboonwong, P., Suttajit, M. \& Chewonarin, T. The effect of Perilla frutescens leaf on 1, 2-dimethylhydrazine-induced initiation of colon carcinogenesis in rats. Journal of Food Biochemistry 42, e12493 (2018).

5. Ku, S.-K., Kwak, S. \& Bae, J.-S. Orientin inhibits high glucose-induced vascular inflammation in vitro and in vivo. Inflammation 37, 2164-2173 (2014).

6. Nguyen, L. H., Goel, A. \& Chung, D. C. Pathways of colorectal carcinogenesis. Gastroenterology 158, 291-302 (2020).

7. Murata, M. Inflammation and cancer. Environmental health and preventive medicine 23, 1-8 (2018).

8. Strzalka, W. \& Ziemienowicz, A. Proliferating cell nuclear antigen (PCNA): a key factor in DNA replication and cell cycle regulation. Annals of botany 107, 1127-1140 (2011).

9. Thangaraj, K. et al. Orientin induces G0/G1 cell cycle arrest and mitochondria mediated intrinsic apoptosis in human colorectal carcinoma HT29 cells. Biomolecules 9, 418 (2019).

10. Zhang, R., Xu, J., Zhao, J. \& Wang, X. Silencing of hsa_circ_0007534 suppresses proliferation and induces apoptosis in colorectal cancer cells. Eur Rev Med Pharmacol Sci 22, 118-126 (2018).

11. Chansriniyom, C. et al. Tandem mass spectrometry of aqueous extract from Ficus dubia sap and its cell-based assessments for use as a skin antioxidant. Scientific reports 11, 1-13 (2021).

12. Rodthayoy, D. et al. Effect of Ficusdubia latex and root extracts in lipopolysaccharide-induced macrophages. Innovation of Functional Foods in Asia (IFFA), 205 (2018).

13. Li, R. W. et al. A new anti-inflammatory glucoside from Ficus racemosa L. Planta medica 70, 421426 (2004).

14. Veerapur, V. et al. Ficus racemosa stem bark extract: a potent antioxidant and a probable natural radioprotector. Evidence-Based Complementary and Alternative Medicine 6, 317-324 (2009). 
15. Badgujar, S. B., Patel, V. V., Bandivdekar, A. H. \& Mahajan, R. T. Traditional uses, phytochemistry and pharmacology of Ficus carica: A review. Pharmaceutical biology 52, 1487-1503 (2014).

16. Soltana, H. et al. Antitumoral activity of Ficus carica L. on colorectal cancer cell lines. Cellular and Molecular Biology 65, 6-11 (2019).

17. Megaraj, V. et al. Role of hepatic and intestinal p450 enzymes in the metabolic activation of the colon carcinogen azoxymethane in mice. Chemical research in toxicology 27, 656-662 (2014).

18. Coussens, L. M. \& Werb, Z. Inflammation and cancer. Nature 420, 860-867, doi:10.1038/nature01322 (2002).

19. Sugiyama, M. et al. Localisation of apoptosis and expression of apoptosis related proteins in the synovium of patients with rheumatoid arthritis. Annals of the rheumatic diseases 55, 442-449 (1996).

20. Sirisha, N., Sreenivasulu, M., Sangeeta, K. \& Chetty, C. M. Antioxidant properties of Ficus species-a review. International journal of pharmtech research 2, 2174-2182 (2010).

21. Lv, H. et al. Phytochemical compositions and antioxidant and anti-inflammatory activities of crude extracts from Ficus pandurata H.(Moraceae). Evidence-Based Complementary and Alternative Medicine 2013 (2013).

22. Ali, B. et al. Anti-inflammatory and antioxidant activity of Ficus carica Linn. leaves. Natural product research 26, 460-465 (2012).

23. El-hawary, S. S., Ali, Z. Y. \& Younis, I. Y. Hepatoprotective potential of standardized Ficus species in intrahepatic cholestasis rat model: Involvement of nuclear factor-KB, and Farnesoid $\mathrm{X}$ receptor signaling pathways. Journal of Ethnopharmacology 231, 262-274; 10.1016/j.jep.2018.11.026 (2019).

24. Çalişkan, O. \& Polat, A. A. Phytochemical and antioxidant properties of selected fig (Ficus carica L.) accessions from the eastern Mediterranean region of Turkey. Scientia Horticulturae 128, 473-478 (2011).

25. Khadhraoui, M., Bagues, M., Artés, F. \& Ferchichi, A. Phytochemical content, antioxidant potential, and fatty acid composition of dried Tunisian fig (Ficus carica L.) cultivars. Journal of Applied Botany and Food Quality 92, 143-150 (2019).

26. Hou, N., Liu, N., Han, J., Yan, Y. \& Li, J. Chlorogenic acid induces reactive oxygen species generation and inhibits the viability of human colon cancer cells. Anti-cancer drugs 28, 59- 65 (2017).


presents antitumor activity in HT-29 human colon cancer in vitro and in vivo. Molecular \& Cellular Toxicology 11, 457-463 (2015).

28. Suttisansanee, U. et al. Health-promoting bioactivity and in vivo genotoxicity evaluation of a hemiepiphyte fig, Ficus dubia. Food Science \& Nutrition 9, 2269-2279; 10.1002/fsn3.2205 (2021).

29. Pretlow, T. P. \& Pretlow, T. G. Mutant KRAS in aberrant crypt foci (ACF): initiation of colorectal cancer? Biochimica et Biophysica Acta (BBA)-Reviews on Cancer 1756, 83-96 (2005). 
30. Sengottuvelan, M., Viswanathan, P. \& Nalini, N. Chemopreventive effect of trans-resveratrol-a phytoalexin against colonic aberrant crypt foci and cell proliferation in 1, 2-dimethylhydrazine induced colon carcinogenesis. Carcinogenesis 27, 1038-1046 (2006).

31. Kilari, B. P., Kotakadi, V. S. \& Penchalaneni, J. Anti-proliferative and apoptotic effects of Basella rubra (L.) Against 1, 2-Dimethyl Hydrazine-induced colon carcinogenesis in rats. Asian Pacific Journal of Cancer Prevention 17, 73-80 (2016).

32. Summart, R. \& Chewonarin, T. Purple rice extract supplemented diet reduces DMH-induced aberrant crypt foci in the rat colon by inhibition of bacterial $\beta$-glucuronidase. Asian Pacific Journal of Cancer Prevention 15, 749-755 (2014).

33. Cheng, L. \& Lai, M.-D. Aberrant crypt foci as microscopic precursors of colorectal cancer. World J Gastroenterol 9, 2642-2649, doi:10.3748/wjg.v9.i12.2642 (2003).

34. Zhu, Q.-C. et al. Effect of a high-fat diet in development of colonic adenoma in an animal model. World journal of gastroenterology: WJG 20, 8119 (2014).

35. Pallem, P. V. S. P., Bodiga, S. \& Bodiga, V. L. Dietary phytate lowers K-ras mutational frequency, decreases DNA-adduct and hydroxyl radical formation in azoxymethane-induced colon cancer. Iranian journal of basic medical sciences 23, 20 (2020).

36. Senapathy, J. G., Jayanthi, S., Viswanathan, P., Umadevi, P. \& Nalini, N. Effect of gallic acid on xenobiotic metabolizing enzymes in 1, 2-dimethyl hydrazine induced colon carcinogenesis in Wistar rats-a chemopreventive approach. Food and chemical toxicology 49, 887-892 (2011).

37. Fisher, M. B., Paine, M. F., Strelevitz, T. J. \& Wrighton, S. A. The role of hepatic and extrahepatic UDPglucuronosyltransferases in human drug metabolism*†. Drug Metabolism Reviews 33, 273-297, doi:10.1081/DMR-120000653 (2001).

38. Weisburger, J. H. Colon carcinogens: Their metabolism and mode of action. Cancer 28, 60-70; 10.1002/1097-0142(197107)28:1 (1971).

39. Manoj, G., Thampi, B., Leelamma, S. \& Menon, P. Effect of dietary fiber on the activity of intestinal and fecal beta-glucuronidase activity during 1,2-dimethylhydrazine induced colon carcinogenesis. Plant Foods for Human Nutrition 56, 13-21 (2001).

40. Azcárate-Peril, M. A., Sikes, M. \& Bruno-Bárcena, J. M. The intestinal microbiota, gastrointestinal environment and colorectal cancer: a putative role for probiotics in prevention of colorectal cancer? American Journal of Physiology-Gastrointestinal and Liver Physiology 301, G401-G424 (2011).

41. Exon, J. H., Magnuson, B. A., South, E. H. \& Hendrix, K. Effect of dietary chlorogenic acid on multiple immune functions and formation of aberrant crypt foci in rats. J Toxicol Environ Health A 53, 375384, doi:10.1080/009841098159231 (1998).

42. Banerjee, N. et al. Plum polyphenols inhibit colorectal aberrant crypt foci formation in rats: potential role of the miR-143/protein kinase B/mammalian target of rapamycin axis. Nutr Res 36, 1105-1113, doi:10.1016/j.nutres.2016.06.008 (2016).

43. Umesalma, S. \& Sudhandiran, G. Differential inhibitory effects of the polyphenol ellagic acid on inflammatory mediators NF-KB, iNOS, COX-2, TNF-a, and IL-6 in 1, 2-dimethylhydrazine-induced rat 
colon carcinogenesis. Basic \& clinical pharmacology \& toxicology 107, 650-655 (2010).

44. Ullman, T. A. \& Itzkowitz, S. H. Intestinal inflammation and cancer. Gastroenterology 140, 18071816. e1801 (2011).

45. Thangaraj, K. \& Vaiyapuri, M. Orientin, a C-glycosyl dietary flavone, suppresses colonic cell proliferation and mitigates NF-кB mediated inflammatory response in 1, 2-dimethylhydrazine induced colorectal carcinogenesis. Biomedicine \& Pharmacotherapy 96, 1253-1266 (2017).

46. Long, A. G., Lundsmith, E. T. \& Hamilton, K. E. Inflammation and colorectal cancer. Current colorectal cancer reports 13, 341-351 (2017).

47. Yu, B., Hu, J., Li, Q. \& Wang, F. CircMAP3K11 contributes to proliferation, apoptosis and migration of human periodontal ligament stem cells in inflammatory microenvironment by regulating TLR4 via miR-511 sponging. Frontiers in Pharmacology 12, 139 (2021).

48. Patel, M. J. et al. A supercritical CO2 extract of neem leaf (A. indica) and its bioactive liminoid, nimbolide, suppresses colon cancer in preclinical models by modulating pro-inflammatory pathways. Molecular carcinogenesis 57, 1156-1165 (2018).

49. Yun, N., Kang, J. W. \& Lee, S. M. Protective effects of chlorogenic acid against ischemia/reperfusion injury in rat liver: molecular evidence of its antioxidant and anti-inflammatory properties. J Nutr Biochem 23, 1249-1255, doi:10.1016/j.jnutbio.2011.06.018 (2012).

50. Holmgren, L., O'Reilly, M. S. \& Folkman, J. Dormancy of micrometastases: balanced proliferation and apoptosis in the presence of angiogenesis suppression. Nature medicine 1, 149-153 (1995).

51. Sadeghi Ekbatan, S., Li, X. Q., Ghorbani, M., Azadi, B. \& Kubow, S. Chlorogenic Acid and Its Microbial Metabolites Exert Anti-Proliferative Effects, S-Phase Cell-Cycle Arrest and Apoptosis in Human Colon Cancer Caco-2 Cells. Int J Mol Sci 19, doi:10.3390/ijms19030723 (2018).

52. Song, F.-L. et al. Total phenolic contents and antioxidant capacities of selected Chinese medicinal plants. International Journal of Molecular Sciences 11, 2362-2372 (2010).

53. Subedi, L. et al. Antioxidant activity and phenol and flavonoid contents of eight medicinal plants from Western Nepal. Journal of Traditional Chinese Medicine 34, 584-590 (2014).

54. Shao, Y., Xu, F., Sun, X., Bao, J. \& Beta, T. Phenolic acids, anthocyanins, and antioxidant capacity in rice (Oryza sativa L.) grains at four stages of development after flowering. Food Chemistry 143, 9096; 10.1016/j.foodchem.2013.07.042 (2014).

55. Bird, R. P. Observation and quantification of aberrant crypts in the murine colon treated with a colon carcinogen: preliminary findings. Cancer letters 37, 147-151 (1987).

56. Chang, T. K., Crespi, C. L. \& Waxman, D. J. in Cytochrome P450 Protocols 127-131 (Springer, 2006).

57. Woodcock, B. \& Wood, G. Effect of protein-free diet on UDP-glucuronyltransferase and sulphotransferase activities in rat liver. Biochemical pharmacology 20, 2703-2713 (1971).

58. Habig, W. H., Pabst, M. J. \& Jakoby, W. B. Glutathione S-transferases: the first enzymatic step in mercapturic acid formation. Journal of biological Chemistry 249, 7130-7139 (1974). 
59. Deeptha, K., Kamaleeswari, M., Sengottuvelan, M. \& Nalini, N. Dose dependent inhibitory effect of dietary caraway on 1, 2-dimethylhydrazine induced colonic aberrant crypt foci and bacterial enzyme activity in rats. Investigational new drugs 24, 479-488 (2006).

60. Iwitzki, F. et al. Nickel (II) inhibits the repair of 06-methylguanine in mammalian cells. Archives of toxicology 72, 681-689 (1998).

\section{Figures}

\section{Figure 1}

HPLC chromatograms of (a) FDLE, (b) The standard of chlorogenic acid and apigenin and (c) FDLE with standard.
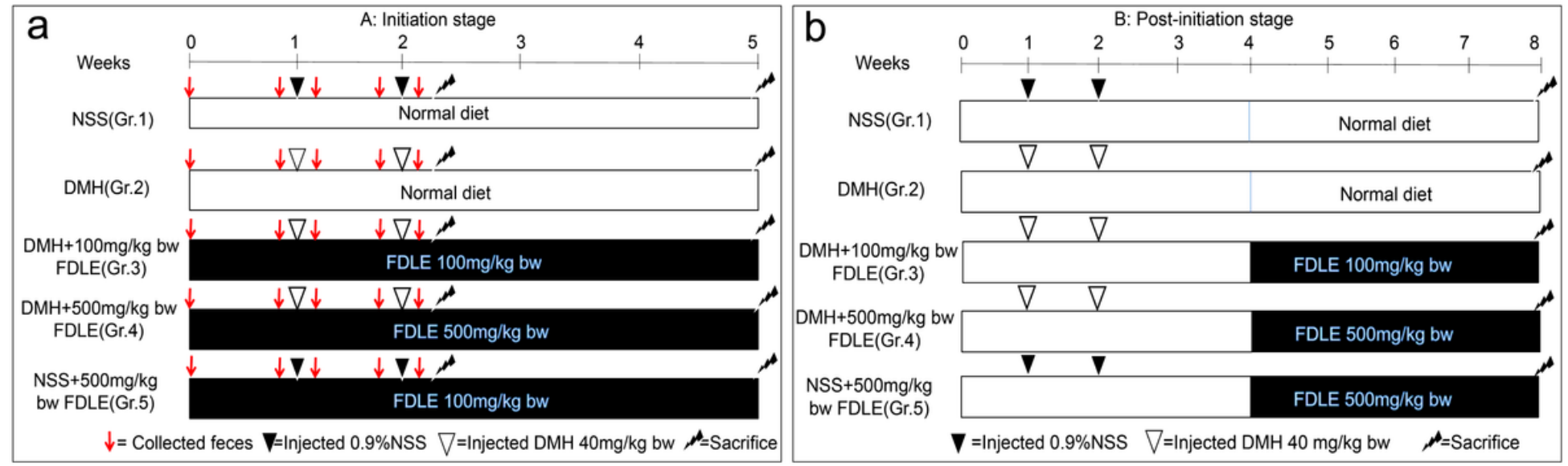

Figure 2

The experimental protocol and treatment schedule. (a) initiation stage and (b) post-initiation stage.

\section{Figure 3}

Effect of FDLE on DMH-induced initiation stage of colon carcinogenesis (a) scheme of inhibitory effect of Ficus dubia latex extract on $\mathrm{DMH}$-induced carcinogenesis. (b) The level of $0^{6}-\mathrm{MeG} \mathrm{DNA}$ adducts in liver tissue and colonic mucosa. (c) The activity of phase I \& II xenobiotic metabolizing enzymes in rat liver tissue, cytochrome P4502E1 (CYP2E1) catalyzed PNP-hydroxylation, (d) UDP-glucuronosyltransferase (UDPGT) and (e) Glutathione-S-transferase (GST), phase II detoxifying enzymes. (f) The activity of bacterial $\beta$-glucuronidase in rat feces. (g) Lineweaver-Burk plot of $E$. coli $\beta$-glucuronidase in the presence 
of FDLE with data representing three independent experiments with similar results. Rat experiments data are presented as the mean $\pm S D$ of five rats per group. ${ }^{*} p<0.05,{ }^{\star *} p<0.01$.

a

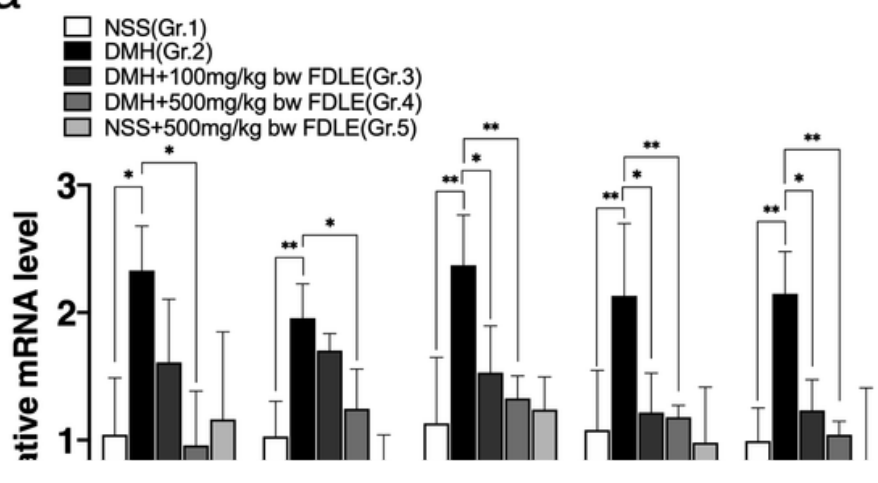

b

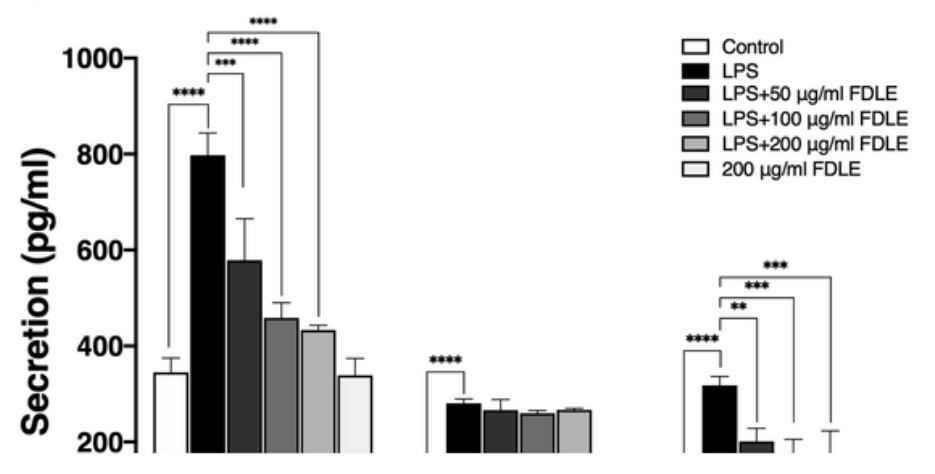

Figure 4

Effects of FDLE on inflammatory process stimulated the colon carcinogenesis in post-initiation rats. (a) Relative mRNA level of pro-inflammatory cytokines and enzymes including IL-1 $\beta$, IL-6, TNF-a, iNOS and COX-2 in rat colonic mucosa. Data are presented as the mean \pm SD of 4 rats per group. (b) The secretion of pro-inflammatory cytokines including TNF-a, IL-1 $\beta$ and IL-6 in LPS induce RAW 264.7 cells treated with FDLE. Relative mRNA levels of pro-inflammatory cytokines, including TNF-a, IL-1 $\beta$ and IL- 6 in cytokines (TNF-a, IFN- $y$ and LPS each $10 \mathrm{ng} / \mathrm{ml}$ ) induced colorectal cancer cell lines at 48 hours. (c) HT-29 cells. (d) HCT-116 cells. Data are presented as the mean $\pm S D$ of three independent experiments which are similar results. ${ }^{*} p<0.05,{ }^{* \star} p<0.01,{ }^{* \star *} p<0.001,{ }^{*} * \star * p<0.0001$ 


\section{Figure 5}

Effect of FDLE on cell proliferation and apoptosis in rat colon mucosa and human colon cancer cells. (a) Immunoblot analysis of PCNA, cleaved caspase-3 and $\beta$-actin proteins. (b) Relative expression of PCNA to $\beta$-actin proteins. (c) Relative expression of cleaved caspase-3 to $\beta$-actin protein. Data are presented as the mean $\pm S D$ of four rats per group. Relative cell proliferation (\%zerotime) of colorectal cancer cell lines with cytokines (TNF-a, IFN- $\gamma$ and LPS each $10 \mathrm{ng} / \mathrm{ml}$ ) or together with FDLE for 24 and 48 hours. (d) HT29 cells. (e) HCT-116 cells. Data are presented as the mean \pm SD of three independent experiments with similar results, ${ }^{*} p<0.05, * * p<0.01,{ }^{* \star *} p<0.001,{ }^{* \star * *} p<0.0001$.

\section{Figure 6}

The chemopreventive mechanism of FDLE in DMH-induced rat colorectal carcinogenesis.

\section{Supplementary Files}

This is a list of supplementary files associated with this preprint. Click to download.

- SupplementaryFigure.docx

- SupplementaryTable.docx

- supplementWesternblotoriginaldata.tiff 